\title{
Article \\ A Life Cycle Sustainability Assessment-Based Decision-Analysis Framework
}

\author{
Marwa Hannouf *(D) and Getachew Assefa \\ Faculty of Environmental Design, University of Calgary, 2500 University Drive NW, Calgary, AB T2N 1N4, \\ Canada; gassefa@ucalgary.ca \\ * Correspondence: mhannouf@ucalgary.ca; Tel.: +1-587-969-6440
}

Received: 7 July 2018; Accepted: 29 September 2018; Published: 24 October 2018

\begin{abstract}
One of the main challenges in using life cycle sustainability assessment (LCSA) is the difficulty of integrating the interrelationships between the three dimensions (environmental, economic and social dimensions) of LCSA results in decision-making toward proposing sustainability improvements for existing product systems. This paper is addressing this challenge by presenting an LCSA-based decision-analysis framework, which is a systematic and structured framework that appraises the pool of potential actions determined based on LCSA results and evaluates their trade-offs to propose potential sustainability solutions. The framework is composed of two parts: (a) LCSA application; (b) decision-analysis approach. The decision analysis part of the framework is built based on some features from previous decision-making approaches and considering the characteristics of LCSA results. The decision-analysis part of the framework, which is the main focus of this study, is divided into five phases to propose and select some recommendations to improve the sustainability performance of product systems. The framework developed is illustrated using results from a previous LCSA case study. The framework can handle the complexity in understanding the interrelationships between the three dimensions of LCSA results, through a structured way of dividing the process into manageable steps. Further work is still needed to apply this framework to a real case study.
\end{abstract}

Keywords: life cycle sustainability assessment; decision-analysis; sustainability improvements; product systems

\section{Introduction}

Sustainable development has gained a deeper understanding since its introduction by the Brundtland report in 1987 [1,2]. However, the definition of the sustainability concept is associated with a much subjectivity and different interpretations and visions among people [2]. Hence, sustainability science has been introduced to advance this discipline and handle its challenges in the contribution to sustainable development (see Sala et al. [2] for an analysis of the current debate on sustainability science). The main challenge in sustainability science has surpassed the problems around sustainability to the path of identifying solutions towards achieving sustainable development [2].

One of the main 17 goals in the 2030 agenda published by the United Nations toward achieving a sustainable world is to "ensure sustainable consumption and production patterns" [3]. With this increased interest in sustainable products, more studies are introducing the sustainability concept and sustainability assessment tools to strategic decision systems in order to improve the sustainability performance of products $[4,5]$.

Different sustainability assessment tools have been proposed in sustainability science $[2,6]$. Among these tools, life cycle thinking (LCT) takes a systemic perspective, which makes it a suitable approach to integrate sustainability into the entire production system [7]. Life cycle 
sustainability assessment (LCSA) is built on the LCT theoretical basis to incorporate sustainable development-oriented information in products' decision-making processes [7,8]. An analysis conducted by Sala et al. [9] has evaluated the LCSA against the main aspects in sustainability science and concluded that even though some improvements are still needed in this framework to cover all aspects of sustainability, it has currently demonstrated its effectiveness for a robust sustainability assessment [9].

The LCSA approach is still a new research area. Recent reviews by Tarne et al. [10] and Onat et al. [11] on the state of LCSA found an increased interest in the topic. Guinee [12] has focused on the challenges and future of the LCSA framework. Multiple challenges were identified such as uncertainty, subjectivity in weighting, double counting, different economic perspectives, etc. [12]. However, the challenges most frequently cited were related to the need for more practical case studies [12], the low maturity of the social life cycle assessment (S-LCA) approach (S-LCA indicators and impact assessment methods) [12] and integrating the interrelationships between the three dimensions (environmental, economic and social dimensions) of LCSA results in decision-making [12-16]. Similar challenges were concluded by Tarne et al. [10], although their challenges were identified for the adoption of LCSA at an automotive company.

This paper is focusing on the LCSA challenge of integrating the interrelationships between the three dimensions (environmental, economic and social dimensions) of LCSA results in decision-making. Integrating the three dimensions of LCSA results is associated with complexity due to the different aspects of sustainability, multiple objectives and existent trade-offs [2,17]. This has led studies to recognize the need for a decision-analysis that can handle this complexity of integrating the LCSA results $[4,18,19]$.

Therefore, some studies (e.g., Ren et al.; Zhang and Haapala; Atilgan and Azapagic) $[4,18,19]$ have addressed this specific challenge by providing a procedure to compare the sustainability performance of different alternatives, through an LCSA multi-criteria decision-analysis framework. This has addressed only part of the challenge, allowing decision-makers to aggregate the LCSA results in a quantitative way and, thus, identify the most sustainable scenario among different alternatives. The goal of this "comparative oriented" integrated assessment widely used in LCSA studies as concluded by Sala et al. [9] is avoiding negative impacts through choosing the option with less negative sustainability impacts. According to UNEP/SETAC [20], this is not the sole purpose of LCSA. LCSA can support companies' decision-makers in different ways; through, for example, comparing the sustainability performance of multiple alternatives (i.e., technologies, scenarios, products) and choosing the most sustainable one, as well as identifying the sustainability impacts along their products' life cycle, which enables finding sustainability improvements in their production systems [20]. Integrating the three pillars of LCSA results to identify problems and appraise potential sustainability improvements in existing product systems, in a systematic and structured way, including the evaluation of the trade-offs associated with potential improvements, is still on the fringe.

Indeed, the major challenge for decision-makers at different levels such as businesses, policy-makers and consumers is to identify the specific actions to be taken to have a higher positive sustainability impact [21,22]. The discussion around finding a practical framework that provides decision-makers with meaningful sustainability information and allows them to identify sustainability improvement opportunities is ongoing. For instance, hotspots analysis (HA) is a framework that is often used to prioritize actions around the sustainability impacts based on different information sources with no in-depth analysis using, for example, previous life cycle studies with experts' opinion [21,22]. This HA framework does not provide a complete and detailed sustainability assessment as is the case in LCSA, but allows an initial prioritization of sustainability impacts. However, still, the main challenge in this framework is to translate the results of the analysis into meaningful sustainability actions and improvements to be used by decision-makers [21,22].

Hannouf and Assefa [23] have presented a first attempt at interpreting the results of LCSA in a combined/integrated fashion in order to propose sustainability improvements for product systems. 
Based on this combined analysis, they identified the challenges and the future research areas required from the LCSA community including the development of a decision-analysis approach that works with LCSA to propose sustainability solutions. This focuses mainly on moving the contribution of LCSA to sustainable production, from solutions that target negative impacts identified through the comparative assessment approach, to solutions that improve the sustainability performance of a product system based on an appraisal of the pool of potential solutions identified for the product system driven by LCSA results in line with the work by Sala et al. [9].

This study is taking an additional step in this area that required further research in answering the following question: How does one use and analyze the interdisciplinary sustainability information derived from LCSA toward guiding decision-makers in developing sustainability improvements for existing product systems?

Moving from sustainability assessment results of LCSA toward practical actions of improving the sustainability performance of product systems goes beyond the interpretation phase of LCSA. This needs a decision-analysis approach that works with LCSA [23] in a systematic and structured way to appraise the pool of potential solutions and evaluate their trade-offs in order to propose potential sustainability solutions. Thus, there is a need for an explicit systematic structured framework that iteratively integrates an LCSA step with a decision analysis step.

This paper is addressing the aforementioned research question by presenting an LCSA-based decision-analysis framework toward sustainability improvements for product systems. At the core of the framework is an explicit and systematic appraisal of the pool of potential actions and solutions that improve different parts of the life cycle of the product systems in terms of the three dimensions of sustainability.

The rest of the paper is structured as follows. Section 2 presents an investigation of some decision-analysis approaches, specifically the structured decision-making (SDM) and multi-criteria decision-analysis (MCDA), to determine the features useful for LCSA-based decision-analysis toward sustainability improvements. Building on this literature and considering the characteristics of LCSA results, Section 3 presents a structured and systematic decision-analysis framework that works best with LCSA results in proposing sustainability improvements. This section explains in detail the process and phases of the framework. Then, this framework is illustrated in Section 4 of this paper using results from a previous case study for the LCSA of high-density polyethylene (HDPE) production in Alberta, Canada, conducted by Hannouf and Assefa [23]. Section 5 presents some discussion and conclusion.

\section{Brief Literature Review on MCDA and SDM Approaches}

MCDA has increasingly been used in various studies to address problems with several conflicting goals, diverse forms of data and multiple interests and perspectives involved in sustainability issues [24]. Despite the existence of several methods for MCDA (see Velasquez and Hester [25] for the common MCDA methods), this process has usually the same structure. The MCDA process starts with the selection of the decision-process, the formulation of options, identifying the objectives and criteria, assessing the alternatives and finally making decisions [26]. In the literature, many terms are used to describe this group of MCDA methods. In this paper, we are considering multicriteria decision analysis (MCDA) and multicriteria decision making (MCDM) as synonyms [17]. For the purpose of this paper, the MCDA term is used consistently.

There are studies that have used LCSA with MCDA to address the multidimensional results of LCSA. Among the MCDA methods used are the analytical hierarchy process (AHP) [27], VIKOR method [28] and Preference Ranking Organization Method for Enrichment Evaluations (PROMETHEE) [29]. For instance, Ren et al. [4] have developed a framework of multi-criteria decision-making for LCSA. After the application of all three tools of LCSA using some specific criteria from each tool, the authors have assigned weights for the different criteria using the AHP method. Then, the VIKOR method is used to determine the sustainability sequence of alternatives. Using an illustrative case study on three bioethanol production pathways, the proposed method by Ren et al. [4] 
can assist decision-makers to choose the most sustainable scenario. The AHP tool of MCDM was also used by Foolmaun and Ramjeawon [30] with LCSA to integrate the three dimensions of sustainability in a case study to compare different scenarios of disposal of used polyethylene terephthalate bottles. The AHP tool was used to assign weights to the three dimensions of sustainability and to the four scenarios in each sustainability dimension. Zhang and Haapala [18] have similarly used MCDA tools with LCSA to integrate the results of the three dimensions and enable the comparison between different scenarios. The authors have specifically used the AHP tool for the assignment of weights and PROMETHEE for the ranking of alternatives. Using an illustrative case study on a work cell for machining a stainless steel knife, the approach developed can help decision-makers and engineers in comparing different production scenarios. In addition, Atilgan and Azapagic [19] have combined LCSA with MCDA to identify the most sustainable electricity option for Turkey. The multi-attribute value theory was used as an MCDA tool to assign weights for the different sustainability aspects in order to calculate an overall sustainability score for each alternative. Moreover, Petrillo et al. [31] have developed an integrated framework based on the application of the three tools of LCSA: life cycle assessment (LCA), life cycle costing (LCC) and S-LCA with the MCDA method of AHP. With the proposed framework, alternatives can be compared based on their sustainability results using a weight analysis through AHP and by calculating a relative sustainability index for each solution. In addition, they have tested this framework on a renewable energy system case study [31].

Many types of MCDA have been used with LCSA with the same objective of assisting decision-makers in comparing the sustainability performance of different alternatives and choosing the most sustainable option. However, using LCSA to assist decision-makers in developing sustainability improvements for their existing product systems in a systematic and structured way including the evaluation of the trade-offs associated with potential improvement solutions is still on the fringe.

SDM "is a broader organizing framework for the environmental management decision process", within which MCDA methods can be used [32]. In contrast to MCDA, SDM gives a higher priority to the role of collaboration and deliberation in the decision process. In addition, it places a higher emphasis on defining and structuring the problems and the importance of analysis in generating management alternatives to achieve the objectives identified in the context of the problems specified.

SDM was introduced as an organized analysis of problems in order to reach decisions that are focused clearly on achieving fundamental objectives [33]. Gregory et al. [32] defined SDM as an organized approach to identify and evaluate creative options and make choices in complex decision situations. It is designed to engage stakeholders, technical experts and decision makers in a process that is both analytical and deliberative, using best practices in decision-making [32]. SDM is rooted in decision theory, which provides a powerful framework for making decisions about the management of complex systems [32]. The steps of the SDM approach have been articulated by several authors; see Bazerman [34] and Gregory et al. [32]. They involve: (1) define the decision context (the problems existing); (2) identify objectives and measures; (3) creating alternatives to achieve the objectives in the context of the problem; (4) examining the consequences of the alternatives, using performance measures in terms of the achievement of objectives; (5) exploring the trade-offs inherent in choosing between the alternatives.

According to Phillips [35], these steps can be revised and refined in order to make it suitable to the context to which it is applied. Examples of previous applications of SDM can be found in natural resource management including management of sustainable harvest from fish [36], management of species [37,38] and climate change [39,40], as well as in corporate purchasing policies [32]. Overall, these applications have demonstrated that the SDM approach is a decision-focused process that helps people to build understanding of a decision problem and to think critically about decisions.

\section{LCSA-Based Decision-Analysis Framework}

Both SDM and MDCA have useful features to address complex problems, but they fall short of being used on their own with LCSA to develop sustainability solutions. The SDM is based on 
the main idea that problems and objectives are a function of decision-makers and stakeholders [32]. This notion is different from using LCSA to inform the definition of problems and objectives. MCDA is based on mathematical modeling of the decision-process and formal quantitative analysis of evaluating alternatives [32]. It therefore cannot capture by itself the full range of the purpose of the decision-analysis approach, which is to develop sustainability solutions for product systems based on both quantitative and qualitative appraisal of the potential pool of solutions.

We are using LCSA to inform and guide decision-makers through a step-by-step development of sustainability solutions for product systems. LCSA provides a systematic and life cycle evaluation of the sustainability impacts in product systems. The LCSA-driven solutions are developed based on a systematic and explicit decision-analysis approach that assists in the understanding of the problems on the three dimensions of sustainability, generation of solutions, evaluation, acceptability and manageability tests and making recommendations. Therefore, the brief literature review on MCDA and SDM presented in Section 2 was used to determine the features relevant for the development of the LCSA-based decision-analysis framework toward sustainability improvements after identifying general characteristics of LCSA results. Then, Table 1 presents the features of SDM and MCDA, which can be used in addressing each of the characteristics of LCSA results from a decision analysis perspective. In constructing the table, making any comparison between SDM and MCDA is not the intention, and while recognizing that MCDA can be used within SDM, in this context, MCDA is treated as a standalone method.

Table 1. Features of multi-criteria decision-analysis (MCDA) and structured decision-making (SDM) useful for LCSA-based decision-analysis versus characteristics of LCSA results.

\begin{tabular}{|c|c|c|}
\hline \multirow{2}{*}{ Characteristics of LCSA Results } & \multicolumn{2}{|c|}{ Features Useful in LCSA-Based Decision-Analysis } \\
\hline & SDM Features & MCDA Features \\
\hline $\begin{array}{l}\text { Multiple dimensions/criteria } \\
\text { (environmental, economic and social) }\end{array}$ & \multicolumn{2}{|c|}{ Capacity to deal with multiple, competing objectives } \\
\hline $\begin{array}{l}\text { - Complex and large amount of results; } \\
\text { specifically the complexity in } \\
\text { understanding the interrelationships } \\
\text { and interactions between the three } \\
\text { dimensions of LCSA results and the } \\
\text { different indicators }\end{array}$ & $\begin{array}{l}\text { Capacity to deal with decisions that involve } \\
\text { complex information (by breaking the } \\
\text { decisions into manageable steps) } \\
\text { Capacity to deal with decisions that involve } \\
\text { a large amount of information }\end{array}$ & $\begin{array}{l}\text { Capacity to combine the different } \\
\text { indicators into one aggregated result } \\
\text { and assign weights for the different } \\
\text { indicators and dimensions }\end{array}$ \\
\hline $\begin{array}{l}\text { Multiple stakeholders in the social } \\
\text { dimension of LCSA results }\end{array}$ & \multicolumn{2}{|c|}{ Capacity to deal with multiple stakeholders and multiple interests } \\
\hline $\begin{array}{l}\text { Different types of results (facts and } \\
\text { values); the facts are related to the } \\
\text { environmental and economic } \\
\text { dimensions, and the values are related } \\
\text { to the social dimension of } \\
\text { LCSA results }\end{array}$ & \multicolumn{2}{|c|}{ Capacity to deal with different types of information and forms of data } \\
\hline $\begin{array}{l}\text { Need for analysis to propose possible } \\
\text { solutions and then evaluate } \\
\text { these options }\end{array}$ & $\begin{array}{l}\text { Analytical and deliberative process to } \\
\text { generate options and management } \\
\text { alternatives }\end{array}$ & $\begin{array}{l}\text { Capacity to evaluate } \\
\text { alternatives/options based on different } \\
\text { criteria } \\
\text { Different methods/tools (to rank } \\
\text { options, assign weights, etc.) }\end{array}$ \\
\hline
\end{tabular}

Building on the previous literature of MCDA and SDM approaches and considering the features identified as useful to address the characteristics of the LCSA results presented in Table 1, a decision-analysis approach that works best with LCSA results to propose sustainability improvements was developed. Figure 1 presents the framework of LCSA with the decision-analysis approach. In Part "a" of this framework, LCSA of products is performed wherein goal and scope definition, inventory analysis, impact assessment and interpretation are conducted for the three tools of LCSA (LCA, LCC and S-LCA). The output of Part "a", which is the LCSA results on the three dimensions of sustainability, is used as input for Part " $\mathrm{b}$ " of the framework. Depending on the situation and context, LCSA results 
may be used in the different phases of the decision-analysis. Part " $b$ " presents the decision-analysis module that includes five phases. The different phases of the decision-analysis approach depicted in Figure 1 correspond also to the decision process steps with agreed criteria by Wrisberg et al. [41] (i.e., issue definition, criteria setting, option generation, option assessment, selection/final decision).

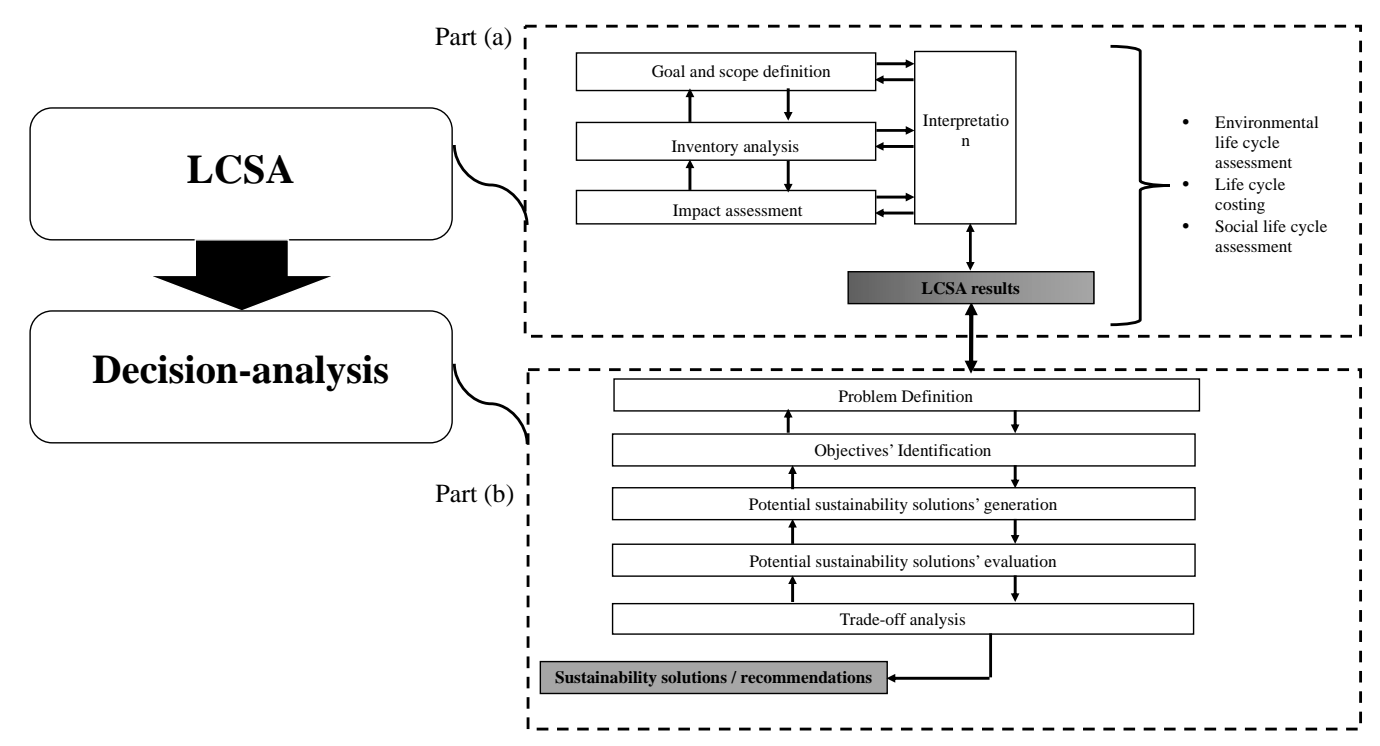

Figure 1. LCSA-based decision-analysis framework.

We explain each of these phases as follows.

The first phase of the problem definition is divided into two steps:

(1) Defining the existing sustainability problems in the product life cycle based on LCSA results. LCSA evaluates the environmental, economic and social impacts of a product's life cycle. As the purpose of the decision-analysis is to propose sustainability improvements for product systems, the economic impacts are determined from the perspective of the producer. The sustainability issues defined in this phase are related to the life cycle stages responsible for the largest amount of environmental, economic and social impacts. Based on the distribution of environmental, economic and social impacts between the stages in each product system, the number of stages focused on may be different to cover the major contribution for each dimension. The sustainability issues also cover the specific cost categories, environmental impact categories and social subcategories/stakeholder groups that largely contribute to the total environmental, economic and social impacts. The LCSA results and thus the sustainability issues defined may be different based on the impact categories considered in each case, the impact assessment method used and the level of aggregation considered in each of the three tools of LCSA.

(2) Stating the purpose of the decision-analysis. As previously mentioned, the main purpose of the framework is to propose sustainability improvements for the product system. However, this can be different within the sustainability model considered to propose these sustainability improvement solutions, when stating the purpose. The two popular sustainability models "weak and strong sustainability" represent the two alternative ways of dealing with the evaluation of the different capitals associated with sustainability and in this case the three dimensions of sustainability. Each model explains the interrelationships between the three dimensions of sustainability from a different perspective [42-44]. Please see Daly [42,43], Neumayer [44] and Hannouf and Assefa [23] for details on the two models.

In the case of considering the weak sustainability model, the purpose will be to propose sustainability improvements along the product life cycle that lead to a refinement in any or all of the three dimensions of sustainability where the degradation of one dimension can be compensated by an 
improvement in another. Sustainability based on this approach is measured as an aggregated value of the improvement of all three dimensions. As there is always uncertainty associated with the values used in life cycle assessment, we recognize that the total reduction achieved by a proposed solution should be higher than the margin of error estimated in each case to be considered as the sustainability solution. The margin of error can reach $25 \%$ for the air and waterborne emissions, industrial solid waste and postconsumer solid waste volume based on Franklin Associates [45]. For the economic impacts, the margin of error should be estimated based on each case; while uncertainty in current economic costs could be of low level, future and long-term economic impacts could have a higher level of uncertainty. For the social impacts, the level of uncertainty could be the highest due to the potential subjectivity around the collection and evaluation of social data; this uncertainty could decrease by using multiple sources of data.

When the strong sustainability model is considered, the purpose will be to propose sustainability improvement solutions along the product life cycle taking reducing environmental impacts as a starting point and evaluating the achievement of benefits in the economic and social dimensions. This follows the main principle of the model, which is considering the environmental dimension as the foundation of sustainability. In this case, the reduction of environmental impacts is a requirement that cannot be substituted by a reduction in any of the other two dimensions. As environmental reductions may be costly, a spatially- or temporally-limited increase in upfront economic costs can be associated with the proposed solutions, but this increase can be compensated by an overall reduction in life cycle costs including long-term reductions in costs. This can be the same for the social impacts. Therefore, based on the strong sustainability model, sustainability improvements should lead to a reduction in environmental impacts higher than the margin of error with a possible increase or decrease in the economic and social impacts; as long as in the case of a limited short-term increase, this increase can either be compensated by a reduction in the overall and long-term social and economic impacts of the product life cycle or stays within an acceptable level of increase that is appropriately defined in each specific context.

In practical terms, decision-makers and stakeholders are key participants in the process of the framework. For example, the purpose is identified within the participation of decision-makers and stakeholders, where interpretations of the sustainability concept could be discussed from the perspective of the two popular sustainability models.

The second phase is to identify the objectives on the three dimensions of sustainability in the context of problems defined in the previous phase. Specifically, the sustainability issues determined are turned into a set of specific objectives. Based on the common goals of LCSA, the overall sustainability objectives are: minimizing the environmental impacts, maximizing the economic benefits (from the perspective of producer) and maximizing the social benefits along the product life cycle. The specific objectives can be different based on each case and relevant to the LCSA results. A table can be used to list the specific objectives related to the three dimensions of sustainability.

The third phase is to generate potential sustainability solutions. This phase is divided into two steps:

(1) Use the value-focused thinking approach to generate options that could be used to achieve each of the specific objectives. The value-focused thinking approach means that options are "designed to address the fundamental values or ends of the decision" (the general objectives in our case) [32]. In this step, we work through the objectives one at a time without consideration of any balance that could be achieved among the objectives through the options proposed. We brainstorm all the possible solutions that could be generated. In real-world companies' decision analysis, this process can include representatives from different departments in the company. However, for the purpose of this paper, this process is mainly based on a literature review of possible solutions that could be used to achieve each of the objectives. For the environmental and economic objectives, a literature review can cover peer-reviewed papers that discuss the environmental and economic impacts of the specific product system and the potential reduction options specifically in the life cycle stages focused on, based on the sustainability issues defined for the product 
system. This includes a search for the most relevant literature focusing on the product system and specifically dealing with the cost categories and environmental impact categories of the product. Regarding the objective under the social dimension, due to the qualitative nature of social results, searching for solutions to achieve the specific objectives could be done based on the social inventory data collected for the product and using some relevant literature for the social areas requiring improvements. Tables can be used at this stage to present the list of general solutions and examples of specific actions. General solutions could be divided into categories based on the main functions of the company, which could differ depending on the type of business.

(2) Create complete potential sustainability strategies by grouping solutions from each specific objective previously identified. A strategy is defined by Porter [46] as "the creation of a unique and valuable position, involving a different set of activities". In this paper, we are using the term "sustainability strategies" to refer to improving the sustainable performance of the company's products through a different set of solutions. This step will generate strategies that meet multiple objectives and opens the opportunity to find creative ways to achieve a balance across objectives. A strategy table can be used here to present and organize the strategies. The strategy table is a "useful structuring and organizing technique for developing strategies" [32]. Actions are grouped along the life cycle stage to form complete potential life cycle stage-based sustainability strategies for each company responsible for specific life cycle stages.

The fourth phase is to determine the effect of the sustainability performance of the strategies proposed on the objectives identified. The evaluation could be done in a quantitative or qualitative way based on the product system and the type of solutions proposed. Performance metrics for the objectives are determined before starting the evaluation of the sustainability performance of each strategy. Trade-offs of the solutions related to different objectives are determined in this step. This phase can be combined with the next phase based on the decision context without affecting the process. It is separately presented for the sake of transparency and accommodating approaches that see the two steps as distinct.

The fifth phase is to look back at and analyze the trade-offs of the solutions in the strategies proposed following the evaluation conducted in the previous phase. The purpose of this phase is to find creative ways to adjust the proposed solutions to manage some of the existent trade-offs and find a balance across the environmental, economic and social objectives. As Porter [46] stated "Trade-offs are essential to strategy", to choose what to do to create a sustainable advantage. Trade-offs are normally competing in a strategy [46]; therefore, this phase includes adjusting the strategies proposed based on the purpose of the decision-analysis stated in the first phase and selecting those solutions meeting the specific criteria of the case. An effective strategy should have a positive performance in multiple areas and work on integrating its activities together [46]. Thus, the adjustment conducted in this phase can help find creative ways to reach a balance across objectives and manage some of the existent trade-offs based on the results of the acceptability test and manageability test carried out on the pool of candidate sustainability solutions. This last phase of the decision-analysis approach is where possible sustainability solutions and recommendations in the form of sustainability strategies for the product system of interest are selected based on the trade-off analysis. However, in real-world decision-making, the process continues with an implementation of the solutions and monitoring of the performance. The process is iterative; therefore, when and if necessary, the decision process is initiated again following a review of the performance of the solutions with a (re)-definition of the problems to adjust these solutions or propose other more appropriate ones.

As shown in Figures 1 and 2 (below), both the LCSA and the decision-analysis are carried out in an iterative way, where it is always possible to go back to the previous stages of the process and make any adjustment whenever needed and then continue with the other stages of the process. Depending on the context or situation, going back to the LCSA part to adjust it is also possible when more information or better information is found for use as input to the decision-analysis approach for better decisions. 
In practice, the framework can be applied in two different ways: (1) it can build on existing LCSA studies; therefore, decision-analysts can use this information generated from these studies to conduct the decision-analysis step in defining problems, objectives, etc.; (2) it can initiate the new LCSA studies from the beginning where the iterative process would be supported with the participation of decision-makers and stakeholders along the steps of the framework. Their participation in this case can result in adjusting the LCSA steps with some decisions on the scope, impact categories, impact assessment methods, etc. Therefore, it would be possible and of benefit for the practitioner to discuss the LCSA application and interact with decision-makers and stakeholders before the start of the LCSA process. This discussion can initially guide the practitioner in the application of LCSA and ensure that the concerns of decision-makers and stakeholders are taken into account. This discussion and interaction with decision-makers and stakeholders can give the practitioner as much context on the product system and company with which they are dealing. This would ensure that LCSA provides a clear definition of the existent problems in company's product systems and presents the best information for decision-makers and stakeholders. However, if throughout the decision-analysis process, it was found that more information is needed from the LCSA part, it is always possible to go back to previous steps for more and better information.

Figure 2 summarizes the process of the decision-analysis approach in a graphical way. It explains the process of going from the sustainability issues to the recommended sustainability strategies.

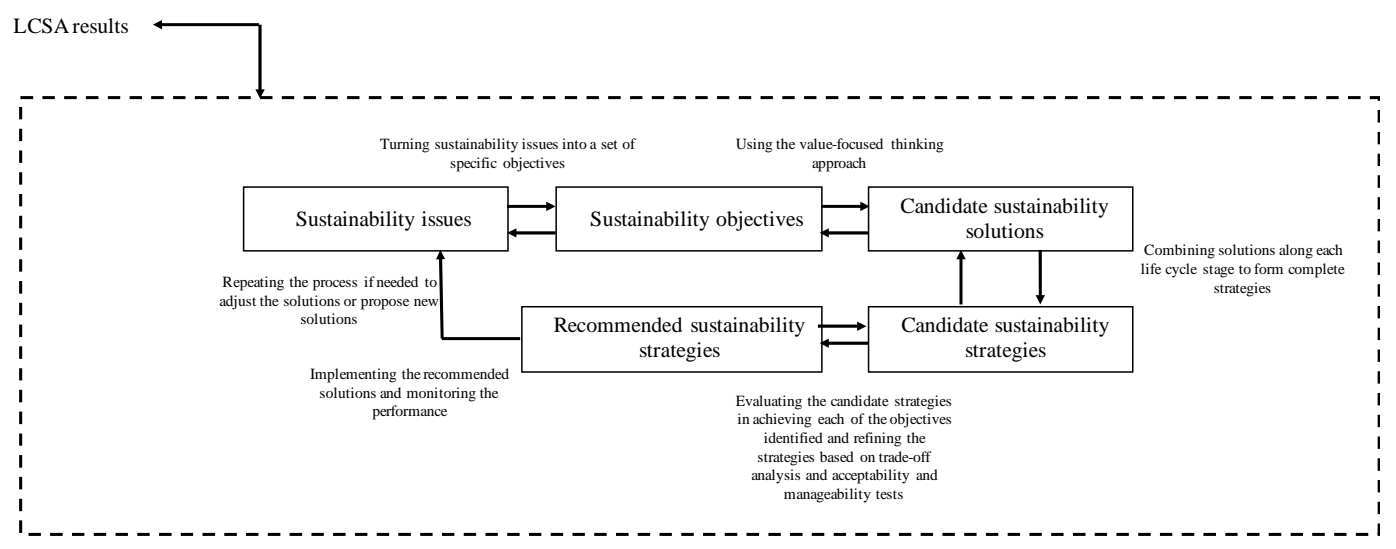

Figure 2. The process of going from the sustainability issues to the recommended sustainability strategies in the decision-analysis approach.

\section{Application of the Framework: An Illustration}

The LCSA case study conducted by Hannouf and Assefa [23] on HDPE production is used in this paper to illustrate the application of the proposed LCSA-based decision-analysis framework toward sustainability improvements. This section summarizes the results of the application of LCSA followed by a demonstrated application of the decision-analysis approach proposed. The intention of this case study is not to present an actual application of the framework or to present specific sustainability solutions for the case study.

\section{1. $L C S A$}

LCSA has been conducted by Hannouf and Assefa [23] to evaluate the environmental, economic and social performance and hotspots of the cradle-to-gate life cycle of HDPE by the Dow Chemical Canada facility. Table 2 below summarizes the categories considered on the three dimensions of sustainability and the main results of LCA, LCC and S-LCA. 
Table 2. Summary of LCSA of HDPE: categories considered and main results (based on Hannouf and Assefa [23]). S-LCA, social life cycle assessment.

\begin{tabular}{|c|c|c|c|}
\hline & LCA & LCC & S-LCA \\
\hline $\begin{array}{l}\text { Categories } \\
\text { considered }\end{array}$ & $\begin{array}{l}\text { - Climate change } \\
\text { (GHG emissions) }\end{array}$ & $\begin{array}{ll}\text { - } & \text { Raw materials } \\
\text { - } & \text { Energy } \\
\text { - } & \text { Labor }\end{array}$ & - $\quad$ All stakeholders and subcategories \\
\hline Main results & $\begin{array}{l}\text { - } \quad \text { Ethylene production stage } \\
\text { - } 43 \% \text { of total GHG" } \\
\text { NG extraction stage " } 27 \% \text { of } \\
\text { total GHG" } \\
\text { - Carbon dioxide: largest } \\
\text { contributor in the ethylene } \\
\text { production stage } \\
\text { Methane: largest contributor } \\
\text { in NG extraction stage }\end{array}$ & $\begin{array}{l}\text { - Ethylene production } \\
\text { stage " } 52 \% \text { of total costs" } \\
\text { - NG extraction stage " } 22 \% \\
\text { of total costs" } \\
\text { - Raw materials costs: } \\
\text { largest contributor of } \\
\text { total costs }\end{array}$ & $\begin{array}{l}\text { - Social hotspots determined include for } \\
\text { example for ethylene production stage: } \\
\text { health and safety (consumers), end of } \\
\text { life responsibility, local employment. } \\
\text { Stakeholder groups responsible for } \\
\text { the largest number of social hotspots } \\
\text { determined include for example for } \\
\text { the ethylene production stage: } \\
\text { consumers and the local community }\end{array}$ \\
\hline
\end{tabular}

Abbreviations: GHG: greenhouse gas; NG: natural gas.

\subsection{Decision-Analysis}

In this subsection, the LCSA results are used to illustrate the decision-analysis approach composed of the five steps of problem definition, objective identification, generation of potential solutions, evaluation of generated solutions and trade-off analysis.

\section{(i) Problem definition}

The effort of identifying and defining the issues associated with the cradle-to-gate life cycle HDPE covered LCSA-based evaluation, which includes the stages of natural gas and crude oil extraction, natural gas processing, refining petroleum products, transportation, ethylene production and HDPE production.

Ethylene production and natural gas extraction stages are identified as problem areas of climate change. Carbon dioxide and methane are the problematic gases. The same two stages show also highest cost with raw material cost dominating all cost categories. Under the social dimension, problem areas include for example those that affect local communities (e.g., local employment and cultural heritage) and consumers (e.g., transparency and product's end of life responsibility) for ethylene production stage.

\section{(ii) Objectives' identification}

Overall, objectives can be grouped as environmental objectives, economic objectives and social objectives that strive to minimize GHG emissions, maximize economic benefits and maximize social benefits along the cradle-to-gate life cycle of HDPE, respectively. Building on the problem definition, a strong sustainability model-inspired decision analysis approach seeks to develop specific objectives that encompass sustainability improvements that can reduce GHG emissions in the two stages while reducing costs/increasing revenue and improving the social conditions along the product system's life cycle.

Table 3 presents the list of specific objectives that need to be achieved. This set of objectives has been identified in the context of the issues defined in the previous step. 
Table 3. List of specific objectives.

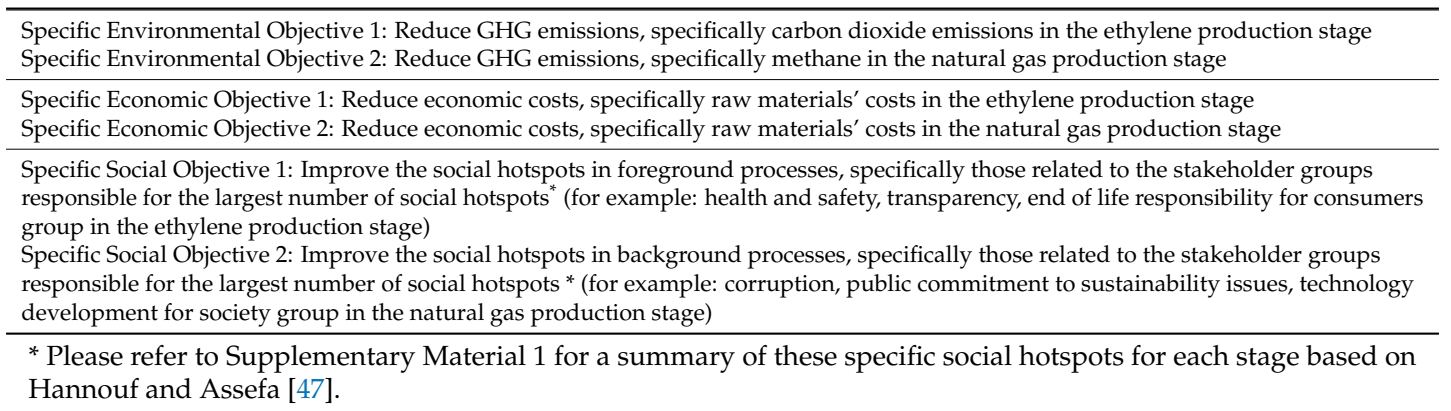

This set of objectives serve as the basis for identifying and evaluating the performance of the potential sustainability solutions that will be proposed in the next step.

(iii) Potential sustainability solutions' generation

Generation of potential sustainability solutions follows two steps: (1) proposing potential solutions to achieve each of the specific objectives (2) grouping of solutions to form potential sustainability strategies. These two steps are detailed as follows.

First, potential solutions are proposed based on a literature review, specifically peer-reviewed papers discussing the GHG emissions associated with ethylene production and natural gas production and along the supply chain, taking into account the specific life cycle of HDPE in this case study as much as possible. For minimizing economic costs, we use literature discussing the cost management practices and cost saving opportunities specifically for the case study product, in the petrochemical industry and across the supply chain. For improving the social hotspots in foreground and background processes, potential solutions/actions proposed were based on the social inventory data collected in Hannouf and Assefa [47] at the company level, sector level (from product social impact life cycle assessment (PSILCA)) or country level.

The main functions of a typical company (i.e., production, research and development, human resource management, purchasing, marketing, accounting and finance) are used to categorize the general potential solutions related to the environmental and economic dimensions. Given that the social issues are related to the stakeholder groups, these general solutions are categorized into foreground and background processes. Some examples of specific actions that could be taken under each general solution are also included. Table 4 is an extract of the possible general solutions to achieve Specific Environmental Objective 1. Tables presenting identified general solutions with examples of specific actions to achieve the specific objectives are in Supplementary Material 2. The tables do not provide an exhaustive list of solutions/actions. Additional ones could be proposed and categorized into the main functions of the company.

Second, solutions from all specific objectives are grouped to form potential life cycle stage-based sustainability strategies. Table 5 presents two groups of solutions with one focusing on the ethylene production stage utilizing potential solutions for achieving a reduction in GHG emissions, reduction in economic costs and improvement in the social performance of the social hotspots in foreground processes, which include the ethylene production stage. The second strategy aims at the natural gas production stage and is composed of potential solutions for achieving a reduction in GHG emissions, reduction in economic costs and improvement in the performance of the social hotspots in this stage.

(iv) Evaluation of potential sustainability solutions

In this phase, the sustainability performance of the strategies proposed against the objectives identified are evaluated. Specific performance metrics for the objectives to assess where the strategy stands with respect to each objective are developed. Table 6 presents the performance metrics for 
environmental, economic and social objectives. The performance metrics used in this illustration are qualitative (i.e., increase or reduction), as quantitative performance evaluation is not possible.

Using the performance metrics identified in Table 6, we evaluated the effect of each general solution proposed to achieve each of the six specific objectives on the three overall objectives. Table 7 is an extract of such an evaluation for the two targeted life cycle stages. Please refer to Supplementary Material 3 for a complete version of the evaluation table.

\section{(v) Trade-off analysis}

The central purpose of the decision-analysis inspired by the strong sustainability model in this illustration is to propose sustainability improvements along the HDPE cradle-to-gate life cycle that can reduce GHG emissions while reducing costs/increasing revenue and improving the social conditions along the product system's life cycle. As previously mentioned, sustainability improvements can lead to a reduction in environmental impacts higher than the margin of error with a possible increase or decrease in the economic and social impacts; as long as a limited short-term increase can either be compensated by a reduction in the overall and long-term social and economic impacts of the product life cycle or stays within an acceptable level of increase that is appropriately defined for each specific context.

Based on the evaluation conducted in the previous section, we can find creative ways to adjust some of the proposed solutions to find a balance between the overall environmental, economic and social objectives and manage some of the existent trade-offs. The process of the trade-off analysis in Figure 3 was followed in reviewing the life cycle stage-focused strategies. The process subjects all the proposed solutions that reduce GHG emissions to a three-step what-if acceptability tests and related manageability tests:

- $\quad$ Acceptability Test 1: If the proposed solutions can be adjusted to achieve a balance across all three overall objectives, accept these solutions. For example, the collaboration through the supply chain actions that target a reduction in GHG while improving the relation with suppliers can be adjusted to achieve a reduction in upfront costs, as well. This could be done by considering the costs and GHG emissions reductions as part of the collaboration with suppliers.

- Acceptability Test 2: If the proposed solutions can be adjusted to achieve a balance across two, but not all three overall objectives, conduct a manageability test and take one of the following two options: Option 1: If the remaining trade-offs are manageable, accept the solutions. Manageability test illustration: The employees' engagement actions can be adjusted to target a reduction in GHG emissions while improving, for example, the working conditions of employees. This can achieve a reduction in GHG and improvement in the relationship with employees, with an increase in upfront costs. However, this increase in upfront costs is still manageable, as it can either be compensated by a reduction in the overall and long-term economic impacts of the product life cycle or it stays within an acceptable level of increase that is appropriately defined for each specific context. Option 2: If the remaining trade-offs are not manageable, these solutions are rejected. Manageability test illustration: The operational improvement actions can be adjusted to attain a reduction in GHG emissions through an improvement in the relationship with workers (improving the working conditions). However, this is associated with an increase in upfront costs, which is not manageable given the absence of compensation by a reduction in the overall and long-term economic impacts of the product life cycle or it exceeds the acceptable level of increase that is appropriately defined for each specific context.

- Acceptability Test 3: If the solutions cannot be adjusted to strike a balance across all three objectives, conduct a manageability test and follow one of the two options below: Option 1: If the trade-offs are still manageable, these solutions are accepted. Manageability test illustration: The maintenance actions that target a reduction in GHG emissions through non-raw materials or energy aspects can achieve a reduction in GHG, an increase in upfront costs and no impact on the social dimension. However, this increase in upfront costs is still acceptable as it can either 
be compensated by a reduction in the overall and long-term economic impacts of the product life cycle or it stays within an acceptable level of increase that is appropriately defined for each specific context. Option 2: If the trade-offs are not manageable, these solutions are rejected. Manageability test illustration: The technology development actions that target a reduction in GHG emissions through non-raw materials or energy aspects can achieve a reduction in GHG with an improvement in the relation with the local community and increase in upfront costs. However, this increase in upfront costs cannot be acceptable as it cannot be compensated by a reduction in the overall and long-term economic impacts of the product life cycle or it exceeds the acceptable level of increase that is appropriately defined for each specific context.

Please refer to Supplementary Material 4 for a table that presents the general solutions of both strategies under the ethylene production stage and natural gas production stage after the adjustment that has been done to propose the sustainability recommendations. Table 8 is an extract of the complete table.

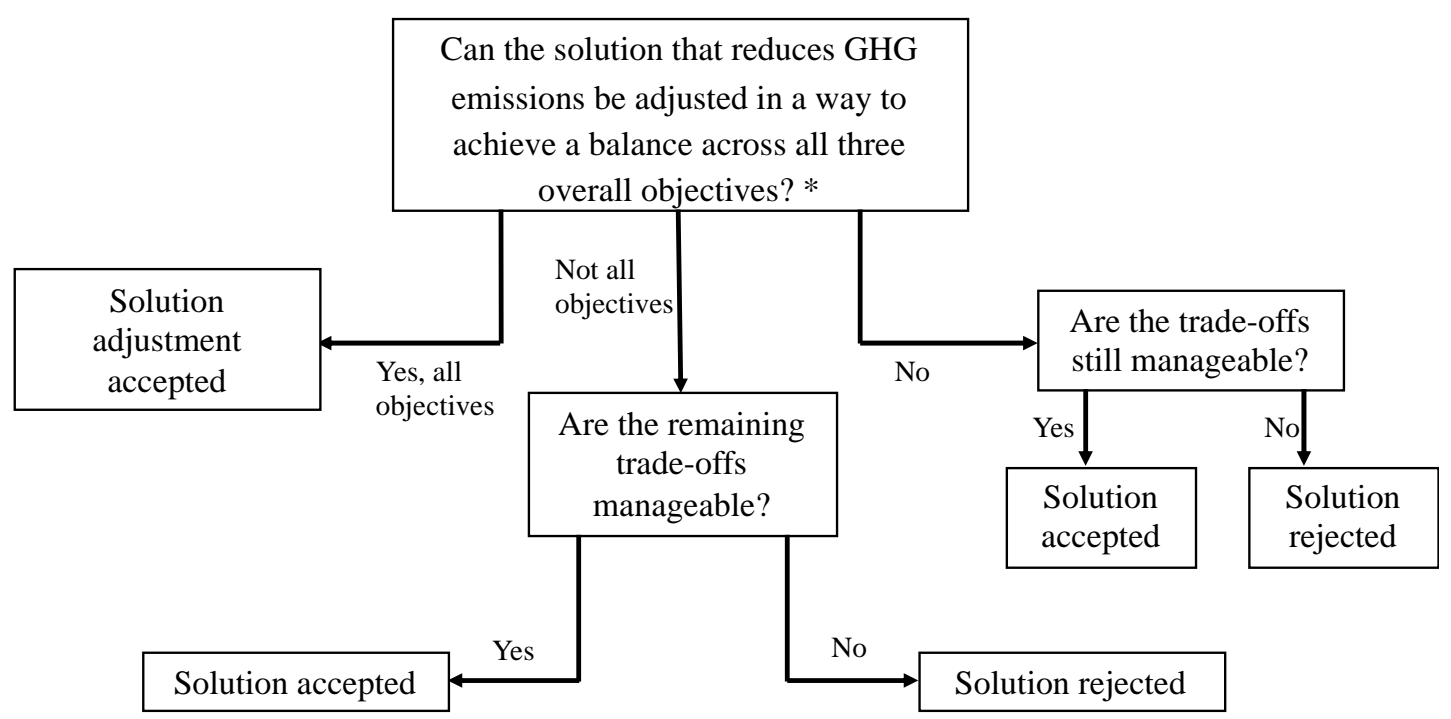

Figure 3. Process steps of the trade-off analysis; * the reduction of GHG emissions should be higher than the margin of error considered in the case study. 
Table 4. An extract of the possible general solutions to achieve Specific Environmental Objective 1 of reducing GHG emissions, specifically carbon dioxide emissions in the ethylene production stage.

\begin{tabular}{|c|c|c|c|}
\hline & Specific Environmental O & e 1: Reduce GHG Emissions, Specifically Carbon Dioxide Emissions in the Ethylene Production Stage & \\
\hline Categories of Solutions & General Solutions & Examples of Specific Actions & Sources \\
\hline \multirow[t]{3}{*}{ Production function (operations) } & Maintenance & $\begin{array}{l}\text { - Reduce equipment leakage: for example maintenance and repair of pressure safety valves and } \\
\text { automated air/fuel ratio controls for combustion } \\
\text { - Operations and maintenance improvements in steam system efficiency } \\
\text { - Maintenance to improve heat recovery rates }\end{array}$ & Yao et al. [48] \\
\hline & Operational improvements & - Maintain optimal operational conditions (process optimization) & Yao et al. [48] \\
\hline & & - Energy-efficiency improvements & Neelis et al. [49] \\
\hline \multirow[t]{2}{*}{ Research and development function } & Technology development & - Carbon dioxide capture and storage & Middleton et al. [50] \\
\hline & & $\begin{array}{l}\text { - Use of renewable energy sources } \\
\text { - Deployment of green technologies }\end{array}$ & Ghanta et al. [51] \\
\hline
\end{tabular}


Table 5. Groups of solutions to form complete potential sustainability strategies achieving specific objectives related to the three overall objectives.

\begin{tabular}{|c|c|}
\hline Ethylene Production Stage-Focused Strategy & Natural Gas Production Stage-Focused Strategy \\
\hline $\begin{array}{l}\text { Specific Environmental Objectives 1: Reduce GHG emissions, specifically carbon dioxide emissions in the } \\
\text { ethylene production stage }\end{array}$ & $\begin{array}{l}\text { Specific Environmental Objectives 2: Reduce GHG emissions, specifically methane in the natural gas } \\
\text { production stage }\end{array}$ \\
\hline 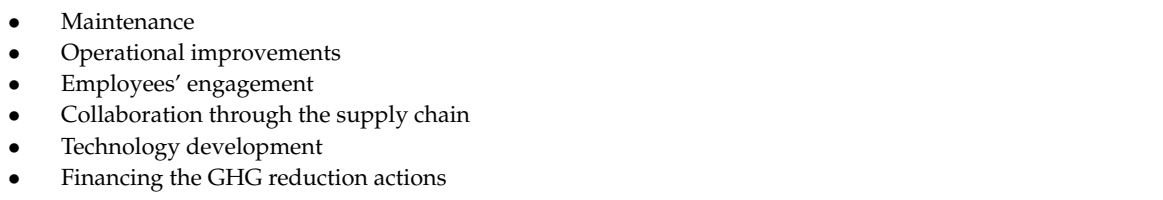 & \\
\hline $\begin{array}{l}\text { Specific economic Objectives 1: Reduce economic costs, specifically raw materials costs in the ethylene } \\
\text { production stage }\end{array}$ & $\begin{array}{l}\text { Specific Economic Objectives 2: Reduce economic costs, specifically raw materials costs in the natural gas } \\
\text { production stage }\end{array}$ \\
\hline $\begin{array}{ll}\text { - } & \text { Maintenance } \\
\text { - } & \text { Operational improvements } \\
\text { - } & \text { Collaboroes' engagement through the supply chain } \\
\text { - } & \text { Echnology development } \\
& \text { Economic management }\end{array}$ & \\
\hline $\begin{array}{l}\text { Specific Social Objectives 1: Improve the social hotspots in foreground processes, specifically those related to the } \\
\text { stakeholder groups responsible for the largest number of social hotspots }\end{array}$ & $\begin{array}{l}\text { Specific Social Objectives 2: Improve the social hotspots in background processes (only in the natural gas } \\
\text { production stage), specifically those related to the stakeholder groups responsible for the largest number of } \\
\text { social hotspots }\end{array}$ \\
\hline $\begin{array}{l}\text { - Improving the social areas that need a high level of improvements in the foreground processes } \\
\text { Improving the social areas that need some level of improvements in the foreground processes } \\
\text { Consumers } \\
\text { Health and safety (consumers) } \\
\text { Transparency } \\
\text { End of life responsibility } \\
\text { Local community } \\
\text { Cultural heritage } \\
\text { Secure living conditions } \\
\text { Safe and healthy living conditions } \\
\text { Local employment }\end{array}$ & $\begin{array}{l}\text { - Improving the social areas that need a high level of improvements in the "natural gas extraction" stage } \\
\text { Society } \\
\text { Corruption } \\
\text { Public commitment to sustainability issues } \\
\text { Technology development } \\
\text { Workers } \\
\text { Discrimination } \\
\text { Social benefits } \\
\text { Freedom of association } \\
\text { Local community } \\
\text { Migration } \\
\text { Local employment } \\
\text { Respect of indigenous rights } \\
\text { Access to immaterial resources }\end{array}$ \\
\hline
\end{tabular}


Table 6. Performance metrics for the three overall objectives

\begin{tabular}{lll}
\hline \multicolumn{1}{c}{ Overall Objectives } & \multicolumn{1}{c}{ Performance Metrics } \\
\hline $\begin{array}{l}\text { Environmental objective: minimize GHG emissions along the } \\
\text { cradle-to-gate life cycle of HDPE }\end{array}$ & - GHG (reduction or increase) \\
\hline $\begin{array}{l}\text { Economic objective: maximize economic benefits along the } \\
\text { cradle-to-gate life cycle of HDPE }\end{array}$ & $\begin{array}{l}\text { Dollar costs (reduction or increase) } \\
\text { Dollar revenue (reduction or increase) }\end{array}$ \\
\hline $\begin{array}{l}\text { Social objective: maximize social benefits along the cradle-to-gate life } \\
\text { cycle of HDPE }\end{array}$ & $\begin{array}{l}\text { Qualitative improvement or weakening in a specific social area related to a } \\
\text { stakeholder group or in the relation between the company and a specific } \\
\text { stakeholder group }\end{array}$ \\
\hline
\end{tabular}

Table 7. An extract of the evaluation table used to evaluate the performance of the general solutions related to Specific Environmental Objectives 1 and 2 relevant to both life cycle stage-focused strategies.

\begin{tabular}{|c|c|c|c|c|c|c|}
\hline & & & Overall Objectives & & & \\
\hline Specific Objectives & General Solutions & $\begin{array}{l}\text { Minimizing GHG } \\
\text { Emissions }\end{array}$ & Maximizing Economic Benefits & Maximizing Social Benefits & $\underset{\mathrm{a}}{\text { Overall Performance }}$ & Long-Term Benefits ${ }^{b}$ \\
\hline \multirow{2}{*}{$\begin{array}{l}\text { Specific Environmental Objectives } 1 \\
\text { and 2: Reduction of GHG emissions in } \\
\text { the ethylene production stage and } \\
\text { natural gas production stage }\end{array}$} & Maintenance & Reduce GHG & $\begin{array}{l}\text { - Increase upfront costs } \\
\text { Possible reduction in energy } \\
\text { costs (can achieve a reduction } \\
\text { in raw materials' costs) }\end{array}$ & - & $1 / 3$ & \multirow{2}{*}{$\begin{array}{l}\text { - Improve the health and safety } \\
\text { - } \quad \text { Rer consumers } \\
\text { environmental costs } \\
\text { - Increase long-term revenues }\end{array}$} \\
\hline & Operational improvements & & $\begin{array}{l}\text { - Increase upfront costs } \\
\text { - } \quad \text { cossible reduction in energy } \\
\text { costs (can achieve a reduction } \\
\text { in overall costs) }\end{array}$ & $\begin{array}{l}\text { Possible improvement in the } \\
\text { relationship with workers }\end{array}$ & $1 / 3$ & \\
\hline
\end{tabular}

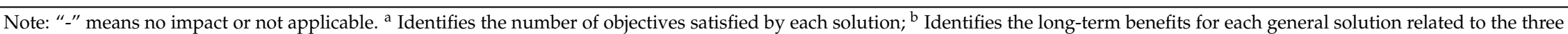
overall objectives. 
Table 8. An extract of the general solutions under the ethylene production stage-focused strategy and natural gas production stage-focused strategy after trade-off analysis.

\begin{tabular}{|c|c|c|c|c|c|c|c|c|}
\hline & \multirow{2}{*}{$\begin{array}{c}\text { General } \\
\text { Solutions }\end{array}$} & \multirow{2}{*}{ Qualification } & \multicolumn{3}{|c|}{ Short-Term Results } & \multirow{2}{*}{ Long-Term Benefits } & \multirow{2}{*}{\multicolumn{2}{|c|}{ Conditions/Comments }} \\
\hline & & & Environmental & Economic & Social & & & \\
\hline \multirow[t]{2}{*}{$\begin{array}{l}\text { Relevant to both } \\
\text { strategies }\end{array}$} & \multirow[t]{2}{*}{ Maintenance } & $\begin{array}{l}\text { Maintenance actions that } \\
\text { target a reduction of GHG } \\
\text { through specifically a } \\
\text { reduction of the use of raw } \\
\text { materials or energy }\end{array}$ & \multirow[t]{2}{*}{ Reduced GHG } & $\begin{array}{l}\text { Reduced energy and raw } \\
\text { materials' costs } \\
\text { Increased upfront costs }\end{array}$ & \multirow[t]{2}{*}{-} & \multirow{2}{*}{$\begin{array}{l}\text { - Improved the health } \\
\text { and safety } \\
\text { for consumers } \\
\text { - Reduced the } \\
\text { environmental costs } \\
\text { - Increased } \\
\text { long-term revenues }\end{array}$} & $\begin{array}{l}\text { The maintenance actions } \\
\text { should target a reduction of } \\
\text { GHG through a reduction of } \\
\text { the use of raw materials } \\
\text { or energy } \\
\text { The reduction of costs of raw } \\
\text { materials or energy can } \\
\text { compensate the increase of } \\
\text { upfront costs that can happen }\end{array}$ & \multirow[t]{2}{*}{$\begin{array}{l}\text { The long-term benefits in } \\
\text { the economic and social } \\
\text { dimensions can } \\
\text { compensate any upfront } \\
\text { economic and social } \\
\text { impacts }\end{array}$} \\
\hline & & $\begin{array}{l}\text { Maintenance actions that } \\
\text { target a reduction of GHG } \\
\text { through non-raw materials } \\
\text { and energy aspects }\end{array}$ & & Increased upfront costs & & & $\begin{array}{l}\text { These maintenance actions } \\
\text { are not associated with a } \\
\text { reduction of upfront costs }\end{array}$ & \\
\hline
\end{tabular}




\section{Discussion and Conclusions}

This paper focuses on the role LCSA can play in enhancing the sustainability performance of product systems and not only on avoiding their negative impacts through the comparative integrated assessment approach widely used in the LCSA area. Integrating the sustainability assessment results of LCSA toward proposing sustainability solutions for existing product systems needs an explicit systematic structured framework that iteratively integrates an LCSA step with a decision analysis step. This study, to our knowledge, is the first of its type to present an LCSA-based decision-analysis framework that is capable of analyzing the interrelationships between the interdisciplinary LCSA results and proposes sustainability improvements for product systems, in a systematic and structured way including the evaluation of the trade-offs associated with potential improvement solutions. At the core of the framework is an explicit and systematic appraisal of the pool of potential actions and solutions that improve different parts of the life cycle of the product systems in terms of the three dimensions of sustainability. The LCSA-driven solutions are developed based on a systematic and explicit decision-analysis approach that assists in the understanding of the problems on the three dimensions of sustainability, the generation of solutions, evaluation, acceptability and manageability tests and making recommendations. The framework presents for decision-makers a new holistic and systematic way of thinking using LCSA around the sustainability problems in their product systems. The purpose of the framework developed is to help decision-makers to analyze the sustainability information derived from the holistic LCSA approach in order to move from analysis results towards practical sustainability solutions.

The framework presented includes two parts: (a) LCSA application and (b) decision-analysis. The decision-analysis part of the framework was developed using some features from previous decision-analysis approaches, specifically the SDM and MCDA, and while considering the characteristics of LCSA results. In addition, the decision-analysis part of the framework, which is the main focus of this study, can handle the complexity in understanding the interrelationships between the three dimensions of LCSA results, through a structured way of dividing the process into manageable steps to propose sustainability improvement strategies in product systems. It is divided into five phases to propose and select some recommendations to improve the sustainability performance of product systems. These recommendations are in the form of life cycle-based sustainability strategies. The framework developed in this paper is illustrated using results from a case study on LCSA of HDPE conducted by Hannouf and Assefa [23]. The purpose of this illustration is to show the application of the process of the framework developed and not to actually develop sustainability solutions for the HDPE case study.

Some challenges and limitations exist in applying the framework. Searching for and finding potential solutions to achieve the specific objectives related to the three dimensions of sustainability could be challenging, especially when trying to be as specific as possible for the case study product. However, one solution to this challenge would be to conduct the case study using primary data and with the collaboration and inputs of the different company's departments, decision-makers and stakeholders that can participate in brainstorming the possible solutions/actions.

Future work still needs to deal with the uncertainty associated with LCSA results in relation to the relevant magnitude of the margin of error, in addition to the uncertainty associated with the evaluation of the long-term benefits of potential sustainability solutions.

In practical terms, the framework is used in situations where decision-makers are searching for improved information on the sustainability impacts of their product systems, in order to make actions to improve the sustainability performance of their products. It is not the intention of this framework to be used in all types of decisions. The applicability of the framework is associated with flexibility, so it can be adjusted depending on the context and situation. In practice, the framework can either initiate LCSA studies from the beginning or build on existing LCSA studies. The former would pave the way for more participation of decision-makers and stakeholders in the different steps of the framework. As previously mentioned, when initiating the process from the beginning, decision-makers 
and stakeholders can have a discussion with the practitioner of LCSA before initiating the study to ensure their concerns are addressed and the specific context of the product system is considered.

The application of the framework conducted in this paper is for illustration purposes only. Applying the framework in real case studies in future work can present more specific solutions and recommendations and not generic ones as those presented in the current application in this paper. The case study chosen in this paper has taken into account only GHG emissions as the impact category for the environmental dimension, as the original work was conducted on one of the large GHG emitters in Alberta, Canada. The need to focus on the climate change impact category for large GHG emitters in general is increasing with the global climate change agreements and the increased environmental awareness on this issue. The case study has taken into account a cradle-to-gate life cycle, including the critical life cycle stages of the product system as required by existing policy regulations on the companies responsible for the foreground system. However, the framework in general is not limited to part of the life cycle of product systems and to a limited number of impact categories.

In addition, applying the framework in real case studies can include further steps such as the implementation of the proposed solutions, monitoring the performance and making any revisions if needed. Despite these challenges, in general, the framework proposed presents an opportunity for decision-makers to select potential sustainability improvements for their products based on a systematic, structured and explicit analysis. Further work is still needed to evaluate and validate the potential of the LCSA-based decision-analysis framework developed in supporting sustainability-based decision-making in product systems and applying the framework on other real case studies. This can identify the strengths and weaknesses of the framework and highlight further improvements needed. In addition, future work may include developing the trade-off analysis process further to create a programming of accept/reject of the sustainability solutions to implement, based on trade-off acceptability and manageability test. This can facilitate the implementation of the framework by companies in the real world.

Supplementary Materials: The following are available online at http:/ /www.mdpi.com/2071-1050/10/11/3863/ s1: SM1: The summary of S-LCA results "social hotspots" for the LCSA of the HDPE case study. SM2: Tables presenting the possible general solutions categorized with examples of specific actions to achieve the specific objectives related to the high-density polyethylene case study. SM3: Tables presenting the complete evaluation of both strategies related to the high-density polyethylene case study. SM4: Table presenting the general solutions under the ethylene production stage-focused strategy and natural gas production stage-focused strategy after trade-off analysis.

Author Contributions: M.H. collected and analyzed the data and drafted the paper. G.A. provided professional and continuous guidance, editing and reviewing for the paper.

Funding: This research was funded by Alberta Innovates Bio Solutions BIO-14-004.

Acknowledgments: This research was undertaken thanks in part to support from the University of Calgary's Canada First Research Excellence Fund Program, the Global Research Initiative in Sustainable Low Carbon Unconventional Resources.

Conflicts of Interest: The authors declare no conflict of interest. The funding sponsors had no role in the design of the study; in the collection, analyses or interpretation of data; in the writing of the manuscript; nor in the decision to publish the results.

\section{References}

1. WCED. Our Common Future; Oxford University Press: New York, NY, USA, 1987.

2. Sala, S.; Farioli, F.; Zamagni, A. Progress in sustainability science: Lessons learnt from current methodologies for sustainability assessment: Part 1. Int. J. Life Cycle Assess. 2013, 18, 1653-1672. [CrossRef]

3. United Nations (UN). Transforming Our World: The 2030 Agenda for Sustainable Development. 2015. Available online: https://sustainabledevelopment.un.org/content/documents/21252030\%20Agenda\% 20for\%20Sustainable\%20Development\%20web.pdf (accessed on 2 February 2018).

4. Ren, J.; Manzardo, A.; Mazzi, A.; Zuliani, F.; Scipioni, A. Prioritization of bioethanol production pathways in China based on life cycle sustainability assessment and multicriteria decision-making. Int. J. Life Cycle Assess. 2015, 20, 842-853. [CrossRef] 
5. Kurka, T. Application of the analytic hierarchy process to evaluate the regional sustainability of bioenergy developments. Energy 2013, 62, 393-402. [CrossRef]

6. Myllyviita, R.; Antikainen, R.; Leskinen, P. Sustainability assessment tools-Their comprehensive and utilization in company level sustainability assessments in Finland. Int. J. Sustain. Dev. World Ecol. 2016, 24, 236-247. [CrossRef]

7. Arcese, G.; Lucchetti, M.C.; Massa, I. Modeling social life cycle assessment framework for the Italiane Wine. J. Clean. Prod. 2017, 140, 1027-1036. [CrossRef]

8. Zamagni, A. Life cycle sustainability assessment. Int. J. Life Cycle Assess. 2012, 17, 373-376. [CrossRef]

9. Sala, S.; Farioli, F.; Zamagni, A. Life cycle sustainability assessment in the context of sustainability science progress (part 2). Int. J. Life Cycle Assess. 2013, 18, 1686-1697. [CrossRef]

10. Tarne, P.; Traverso, M.; Finkbeiner, M. Review of life cycle sustainability assessment and potential for its adoption at an automotive company. Sustainability 2017, 9, 670. [CrossRef]

11. Onat, N.C.; Kucukvar, M.; Halog, A.; Cloutier, S. Systems thinking for life cycle sustainability assessment: A review of recent developments, applications, and future perspectives. Sustainability 2017, 9, 706. [CrossRef]

12. Guinée, J. Life cycle sustainability assessment: What is it and what are its challenges? In Taking Stock of Industrial Ecology; Clift, R., Druckman, A., Eds.; Springer International Publishing: Cham, Switzerland, 2016; pp. 45-68.

13. Traverso, M.; Finkbeiner, M.; Jorgensen, A.; Schneider, L. Life cycle sustainability dashboard. J. Ind. Ecol. 2012, 16, 680-688. [CrossRef]

14. Traverso, M.; Asdrubali, F.; Francia, A.; Finkbeiner, M. Toward life cycle sustainability assessment: An implementation to photovoltaic modules. Int. J. Life Cycle Assess. 2012, 17, 1068-1079. [CrossRef]

15. Bachmann, T.M. Towards life cycle sustainability assessment: Drawing on the NEEDS project's total cost and multi-criteria decision analysis ranking methods. Int. J. Life Cycle Assess. 2013, 18, 1698-1709. [CrossRef]

16. Pesonen, H.L.; Horn, S. Evaluating the sustainability SWOT as a streamlined tool for life cycle sustainability assessment. Int. J. Life Cycle Assess. 2013, 18, 1780-1792. [CrossRef]

17. Luca, A.I.D.; Iofrida, N.; Leskinen, P.; Stillitano, T.; Falcone, G.; Strano, A.; Gulisano, G. Life cycle tools combined with multi-criteria and participatory methods for agricultural sustainability: Insights from a systematic and critical review. Sci. Total Environ. 2017, 595, 352-370. [CrossRef] [PubMed]

18. Zhang, H.; Haapala, K.R. Integrating sustainability manufacturing assessment into decision making for a production work cell. J. Clean. Prod. 2015, 105, 52-63. [CrossRef]

19. Atilgan, B.; Azapagic, A. An integrated life cycle sustainability assessment of electricity generation in Turkey. Energy Policy 2016, 93, 168-186. [CrossRef]

20. UNEP; SETAC. Towards Life Cycle Sustainability Assessment: Making Informed Choices on Products. 2011. Available online: http:/ / www.unep.org/pdf/UNEP_LifecycleInit_Dec_FINAL.pdf (accessed on 6 January 2018).

21. Barthel, M.; Fava, J.A.; Harnanan, C.A.; Strothmann, P.; Khan, S.; Miller, S. Hotspots analysis: Providing the focus for action. In Life Cycle Management; Sonnemann, G., Mragni, M., Eds.; Springer: Dordrecht, The Netherlands, 2015; pp. 149-167.

22. UNEP, United Nations Environment Program. Hotspots Analysis: An Overarching Methodological Framework and Guidance for Product and Sector Level Application. 2017. Available online: http: / / curc3r.org/wp-content/uploads/2017/08/Hotspots-Publication.pdf (accessed on 15 March 2018).

23. Hannouf, M.; Assefa, G. Life cycle sustainability assessment for sustainability improvements: A case study on high density polyethylene production in Alberta, Canada. Sustainability 2017, 9, 2332. [CrossRef]

24. Karjalainen, T.P.; Rossi, P.M.; Ala-aho, P.; Eskelinen, R.; Reinikainen, K.; Klove, B.; Pulido-Velazquez, M.; Yang, H. A decision analysis framework for stakeholder involvement and learning in groundwater management. Hydrol. Earth Syst. Sci. 2013, 17, 5141-5153. [CrossRef]

25. Velasquez, M.; Hester, P.T. An analysis of multi-criteria decision making methods. Int. J. Oper. Res. 2013, 10, 56-66.

26. Pohekar, S.D.; Ramachandran, M. Application of multi-criteria decision making to sustainable energy planning-A review. Renew. Sustain. Energy Rev. 2004, 8, 365-381. [CrossRef]

27. Saaty, T.L. The Analytic Hierarchy Process: Planning, Priority Setting, Resource Allocation; McGraw-Hill: New York, NY, USA, 1980. 
28. Opricovic, S.; Tzeng, G.-H. Extended VIKOR method in comparison with outranking methods. Eur. J. Oper. Res. 2007, 178, 514-529. [CrossRef]

29. Behzadian, M.; Kazemzadeh, R.B.; Albadvi, A.; Aghdasi, M. Promethee: A comprehensive literature review on methodologies and applications. Eur. J. Oper. Res. 2010, 200, 198-215. [CrossRef]

30. Foolmaun, R.K.; Ramjeawon, T. Life cycle sustainability assessments (LCSA) of four disposal scenarios for used polyethylene terephthalate (PET) bottles in Mauritius. Environ. Dev. Sustain. 2012, 15, 783-806. [CrossRef]

31. Petrillo, A.; De Felice, F.; Jannelli, E.; Autorino, C.; Minutillo, M.; Lavadera, A.L. Life cycle assessment (LCA) and life cycle cost (LCC) analysis model for a stand-alone hybrid renewable energy system. Renew. Energy 2016, 95, 337-355. [CrossRef]

32. Gregory, R.; Failing, L.; Harstone, M.; Long, G.; McDaniels, T.; Ohlson, D. Structured Decision Making: A Practical Guide to Environmental Management Choices; John Wiley \& Sons: Hoboken, NJ, USA, 2012.

33. Martin, J.; Runge, M.C.; Nichols, J.D.; Lubow, B.C.; Kendall, W.L. Structured decision making as a conceptual framework to identify thresholds for conservation and management. Ecol. Appl. 2009, 19, 1079-1090. [CrossRef] [PubMed]

34. Bazerman, M. Judgement in Managerial Decision Making; Wiley: New York, NY, USA, 2001.

35. Phillips, L.D. A theory of requisite decision models. Acta Psychol. 1984, 56, 29-48. [CrossRef]

36. Irwin, B.J.; Wilberg, M.J.; Jones, M.L.; Bence, J.R. Applying structured decision making to recreational fisheries management. Fisheries 2011, 36, 113-122. [CrossRef]

37. Gregory, R.; Long, G. Using structured decision making to help implement a precautionary approach to endangered species management. Risk Anal. 2009, 29, 518-532. [CrossRef] [PubMed]

38. Blomquist, S.M.; Johnson, T.D.; Smith, D.R.; Call, G.P.; Miller, B.N.; Thurman, W.M.; McFadden, J.E.; Parkin, M.J.; Boomer, G.S. Structured decision-making and rapid prototyping to plan a management response to an invasive species. J. Fish Wildl. Manag. 2010, 1, 19-32. [CrossRef]

39. Ohlson, D.W.; Mckinnon, G.A.; Hirsch, K.G. A structured decision-making approach to climate change adaptation in the forest sector. For. Chron. 2005, 81, 97-103. [CrossRef]

40. Nichols, J.D.; Koneff, M.D.; Heglund, P.J.; Knuston, M.G.; Seamans, M.E.; Lyons, J.E.; Morton, J.M.; Jones, M.T.; Boomer, G.S.; Williams, B.K. Climate change, uncertainty, and natural resource management. J. Wildl. Manag. 2011, 75, 6-18. [CrossRef]

41. Wrisberg, N.; Udo de Haes, H.A.; Triebswetter, U.; Eder, P.; Clift, R. Analytical Tools for Environmental Design and Management in a Systems Perspective; Kluwer Academic Publishers: Dordrecht, The Netherlands, 2002.

42. Daly, H.E. Ecological Economics and Sustainable Development, Selected Essays of Herman Daly; Edward Elgar Publishing Limited: Cheltenham, UK, 2007.

43. Daly, H.E. Beyond Growth: The Economics of Sustainable Development; Beacon Press: Boston, MA, USA, 1996.

44. Neumayer, E. Weak Versus Strong Sustainability: Exploring the Limits of Two Opposing Paradigms; Edward Elgar Publishing Limited: Cheltenham, UK, 2013.

45. Franklin Associates. Life Cycle Inventory of Three Single-Serving Soft Drink Containers. Revised Peer Reviewed Final Report. 2009. Available online: http://www.petresin.org/pdf/ FranklinLCISodaContainers2009.pdf (accessed on 26 February 2018).

46. Porter, M.E. What Is Strategy? Harvard Business Review. 1996. Available online: http://strategus.it/files/ What-is-strategy---Porter.pdf (accessed on 26 February 2018).

47. Hannouf, M.; Assefa, G. Subcategory assessment method for social life cycle assessment: A case study of high density polyethylene production in Alberta, Canada. Int. J. Life Cycle Assess. 2018. [CrossRef]

48. Yao, Y.; Graziano, D.J.; Riddle, M.; Cresko, J.; Masanet, E. Understanding variability to reduce the energy and GHG footprints of U.S. ethylene production. Environ. Sci. Technol. 2015, 48, 14704-14716. [CrossRef] [PubMed]

49. Neelis, M.; Worrell, E.; Masanet, E. Energy Efficiency Improvement and Cost Saving Opportunities for the Petrochemical Industry. An Energy Star Guide for Energy and Plant Managers. 2008. Available online: https:/ / www.energystar.gov/ia/business/industry/Petrochemical_Industry.pdf (accessed on 23 January 2018). 
50. Middleton, R.S.; Levine, J.S.; Bielicki, J.M.; Viswanathan, H.S.; Carey, J.W.; Stauffer, P.H. Jumpstarting commercial-scale $\mathrm{CO}_{2}$ capture and storage with ethylene production and enhanced oil recovery in the US Gulf. Greenh. Gases Sci. Technol. 2015, 5, 241-253.

51. Ghanta, M.; Fahey, D.; Subramaniam, B. Environmental impacts of ethylene production from diverse feedstocks and energy sources. Appl. Petrochem. Res. 2014, 4, 167-179. [CrossRef]

(C) 2018 by the authors. Licensee MDPI, Basel, Switzerland. This article is an open access article distributed under the terms and conditions of the Creative Commons Attribution (CC BY) license (http:/ / creativecommons.org/licenses/by/4.0/). 